Article

\title{
The GFZ GRACE RL06 Monthly Gravity Field Time Series: Processing Details and Quality Assessment
}

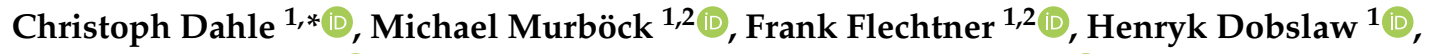 \\ Grzegorz Michalak ${ }^{1}{ }^{\mathbb{D}}$, Karl Hans Neumayer ${ }^{1}$, Oleh Abrykosov ${ }^{1,+}{ }^{-0}$, Anton Reinhold ${ }^{1}$, \\ Rolf König $^{1}$ (D), Roman Sulzbach ${ }^{1,3}$ (D) and Christoph Förste ${ }^{1}$ (D) \\ 1 Department 1: Geodesy, GFZ German Research Centre for Geosciences, 14473 Potsdam, Germany; \\ michael.murboeck@gfz-potsdam.de (M.M.); frank.flechtner@gfz-potsdam.de (F.F.); \\ henryk.dobslaw@gfz-potsdam.de (H.D.); grzegorz.michalak@gfz-potsdam.de (G.M.); \\ karl.neumayer@gfz-potsdam.de (K.H.N.); oleg.abrikosov@gfz-potsdam.de (O.A.); \\ contact@antoncouper.com (A.R.); rolf.koenig@gfz-potsdam.de (R.K.); \\ roman.lucas.sulzbach@gfz-potsdam.de (R.S.); christoph.foerste@gfz-potsdam.de (C.F.) \\ 2 Institute of Geodesy and Geoinformation Science, Technische Universität Berlin, 10623 Berlin, Germany \\ 3 Institute of Meteorology, Freie Universität Berlin, 12165 Berlin, Germany \\ * Correspondence: christoph.dahle@gfz-potsdam.de \\ + Current address: SpaceTech GmbH Immenstaad, 88090 Immenstaad, Germany.
}

Received: 10 August 2019; Accepted: 6 September 2019; Published: 11 September 2019

\begin{abstract}
Time-variable gravity field models derived from observations of the Gravity Recovery and Climate Experiment (GRACE) mission, whose science operations phase ended in June 2017 after more than 15 years, enabled a multitude of studies of Earth's surface mass transport processes and climate change. The German Research Centre for Geosciences (GFZ), routinely processing such monthly gravity fields as part of the GRACE Science Data System, has reprocessed the complete GRACE mission and released an improved GFZ GRACE RL06 monthly gravity field time series. This study provides an insight into the processing strategy of GFZ RL06 which has been considerably changed with respect to previous GFZ GRACE releases, and modifications relative to the precursor GFZ RL05a are described. The quality of the RL06 gravity field models is analyzed and discussed both in the spectral and spatial domain in comparison to the RL05a time series. All results indicate significant improvements of about $40 \%$ in terms of reduced noise. It is also shown that the GFZ RL06 time series is a step forward in terms of consistency, and that errors of the gravity field coefficients are more realistic. These findings are confirmed as well by independent validation of the monthly GRACE models, as done in this work by means of ocean bottom pressure in situ observations and orbit tests with the GOCE satellite. Thus, the GFZ GRACE RL06 time series allows for a better quantification of mass changes in the Earth system.
\end{abstract}

Keywords: satellite gravimetry; GRACE; Level-2 processing; time-variable gravity field; mass change monitoring

\section{Introduction}

During more than 15 years (April 2002 through June 2017) of successful science operations phase, the Gravity Recovery and Climate Experiment (GRACE) mission enabled breakthroughs in monitoring the terrestrial water cycle (e.g., [1,2]), ice sheet and glacier mass balances (e.g., [3,4]), sea-level change (e.g., $[5,6]$ ) and ocean bottom pressure variations (e.g., [7,8]). A comprehensive overview of numerous other GRACE-related studies and their contributions to understanding changes in the global climate system is reviewed by Tapley et al. [9]. These results are based on time-variable, in general monthly, global gravity field models. 
Such models, so-called GRACE Level-2 products, are routinely generated by the joint US-German GRACE Science Data System (SDS) consisting of the Center for Space Research at the University of Texas at Austin (CSR), NASA's Jet Propulsion Laboratory (JPL), and the German Research Centre for Geosciences (GFZ). To provide consistent long-term gravity field time series of highest possible quality to the user community the SDS has recently reprocessed its gravity field solutions over the complete GRACE mission duration. This latest reprocessing, referred to as release 06 (RL06) [10-12], comprises updated background models and processing standards which are also applied to consistently process the first release of gravity field solutions based on data from the GRACE Follow-on (GRACE-FO) mission [13]. The GRACE-FO satellites were successfully launched in May 2018 and are designed to continue the unique GRACE data record for at least five additional years.

Apart from the SDS, recent GRACE gravity field time series are provided by other processing centers, e.g., ITSG-Grace2018 [14], CNES/GRGS RL04 [15], AIUB RL02 [16], or Tongji-Grace2018 [17].

The purpose of this work is to demonstrate the progress that has been achieved with the current GFZ GRACE RL06 time series compared to its precursor GFZ RL05a [18]. First, an overview of the GRACE gravity field processing procedure at GFZ is given and modifications implemented within the RL06 reprocessing are described (Section 2). Thereafter, results are discussed with focus on the internal quality in the spectral and spatial domain comparing RL06 with RL05a (Section 3). Additionally, both time series are validated by external data (Section 4). Finally, conclusions are drawn, and the main findings of this work are summarized (Section 5). All results confirm that GFZ's RL06 time series is a significant step forward in terms of accuracy, consistency and reliability and thus enables a better quantification of climate change related phenomena in the Earth system.

\section{GRACE Level-2 Gravity Field Processing at GFZ}

GRACE global monthly gravity field recovery at GFZ is based on the so-called "dynamical approach" using GFZ's Earth Parameter and Orbit System (EPOS) software package (https:/ / www.gfz-potsdam.de/en/section/global-geomonitoring-and-gravity-field/topics/

earth-system-parameters-and-orbit-dynamics / earth-parameter-and-orbit-system-software-epos/). Underlying satellite orbit perturbations rely on a precise numerical orbit integration taking into account all reference system and force model related quantities [19]. The integrated orbit is then fitted to the GRACE tracking observations, i.e., GPS code and carrier phase observations and K-band inter-satellite ranging data between the two GRACE satellites. This step is done in a least-squares adjustment process solving iteratively for both satellites' state vector at the beginning of each arc, observation-specific parameters, in particular GPS receiver clock offsets, GPS carrier phase ambiguities and calibration parameters for the accelerometers, and other arc-specific parameters such as empirical accelerations. The term "arc" refers to the time length of the integrated orbit starting with one initial state vector which is typically one day. After convergence of the initial orbit adjustment with the a priori force models, the observation equations are extended by partial derivatives for the unknown global parameters describing the gravitational potential, represented by spherical harmonic (SH) gravity field coefficients. Arc-by-arc normal equation (NEQ) systems are generated in this way from the observation equations and accumulated over nominally one month to one overall system which is then solved by matrix inversion. For the complete GRACE mission 163 of these NEQ systems and corresponding Level-2 gravity field products have been derived.

In the following subsections, specific aspects relevant for GRACE gravity field processing are discussed and modifications in GFZ's RL06 processing relative to the processing of the previous release GFZ RL05a are described.

\subsection{GPS Constellation}

Since GPS tracking data are processed, the precise orbits and sender clock offsets of the GPS constellation, nominally consisting of 32 satellites, must be known. Using GFZ's EPOS software, it has been demonstrated by König [20] that an integrated processing of both GPS satellites and the GRACE 
satellites, i.e., simultaneous orbit determination and parameter adjustment at the observation level, is beneficial for the determination of the terrestrial reference frame (TRF). However, the dynamic part of the TRF in König [20] is limited to the SH gravity field coefficients of degrees one and two and all parameters have been estimated daily. When expanding the parameter space of the gravity field to a maximum degree and order (d/o) of 90 or higher, typically for monthly GRACE gravity field solutions, which requires that daily NEQs need to be stacked to obtain a monthly solution, such an integrated approach becomes quite demanding in terms of computational efficiency and proper separation of daily and monthly Earth system and other parameters. Thus, for GRACE gravity field recovery, it is common practice to determine precise GPS orbits and clock offsets beforehand using GPS tracking data from a globally distributed ground station network, and then keep them fixed in the subsequent GRACE orbit and gravity field adjustment process. At GFZ, the GPS constellation used for gravity field determination is traditionally generated in-house allowing for best possible consistency.

For processing GRACE RL06, the GPS constellation has been reprocessed as well. Compared to the previous RL05 GPS constellation, the following changes have been implemented: (1) application of the ITRF2014 reference frame realized by the IGS14 ground station network (https:/ / mediatum.ub.tum. de/doc/1341338/1341338.pdf) instead of ITRF2008/IGS08; (2) increase in the number of GPS ground stations from approx. 70 to approx. 120 to 140; (3) improved solar radiation pressure parameterization; and (4) adaption of the background models according to GRACE RL06 standards (see Section 2.3). To assess the level of accuracy of GFZ's RL05 and RL06 GPS constellations, daily root mean square (RMS) values of position differences regarding final orbits provided by the International GNSS Service (IGS) for all available GPS satellites are calculated. During the GRACE mission period, these 3D RMS values are typically in the range of 3 to $5 \mathrm{~cm}$ in the first years until end of 2006 and around $3 \mathrm{~cm}$ for all years thereafter for the RL06 constellation. The corresponding global 1D RMS over the whole 15 years is $1.96 \mathrm{~cm}$ for RL06 and $2.28 \mathrm{~cm}$ for RL05 revealing that the current RL06 constellation is closer to and more consistent with the official IGS products compared to its predecessor.

\subsection{GRACE Observations}

Both GFZ RL05a and RL06 are based on official GRACE Level-1B (L1B) instrument data processed and provided by JPL [21]. In particular, the following L1B observations are used:

- $\quad$ K-band range-rate (KRR) observations (KBR1B product) as primary observations to retrieve monthly gravity field estimates.

- $\quad$ GPS code and carrier phase observations (GPS1B product) used for precise orbit determination of the GRACE satellites. Please note that inside GFZ's EPOS software, zero-difference ionosphere-free (L3) linear combinations of the measurements are generated and processed.

- Linear accelerations (ACC1B product) to model non-conservative forces acting on the GRACE satellites. Please note that these onboard accelerometer (ACC) observations are not treated as classical observations in a least-squares sense, but only as part of the right-hand side force model.

- Star camera observations (SCA1B product) describing the GRACE satellites' attitude, required for the rotation from the satellite reference frame (SRF) to the inertial frame.

For GFZ RL05a, L1B RL02 data were used. The same RL02 data are used for RL06 in case of ACC1B and GPS1B. Regarding KBR1B and SCA1B, an improved L1B RL03 dataset [22] has been made available by JPL and is used for RL06. At the end of the mission, i.e., during the period November 2016 through June 2017, the ACC instrument aboard GRACE-B was turned off due to battery issues, and thus transplanted ACC observations from GRACE-A have to be used (in the following, this period is denoted by "GRACE single ACC"). For RL05a, a simple ACC data transplant was used, which had only attitude and time corrections applied. As part of JPL's L1B RL03 dataset, an improved transplant version [23], additionally corrected for thruster spikes, has been made available and is used for RL06.

Before orbit and gravity field determination with EPOS, the L1B data are preprocessed as follows for RL05a: (1) KRR observations are modified by adding the light time correction and the antenna 
offset correction (both also taken from the KBR1B products); (2) GPS observations are cleaned, phase cycle slips are detected, and the data are downsampled to $30 \mathrm{~s}$; (3) ACC observations are downsampled from $1 \mathrm{~Hz}$ to $0.2 \mathrm{~Hz}$ by simple decimating and data gaps < $100 \mathrm{~s}$ are interpolated; and (4) data gaps $<500 \mathrm{~s}$ in the SCA1B data are interpolated. For RL06, the only modification concerns (4): SCA1B data are downsampled from $1 \mathrm{~Hz}$ to $0.2 \mathrm{~Hz}$, smoothed and data gaps are filled, all done simultaneously using spherical quadrangle interpolation (SQUAD). After preprocessing, the L1B observations are analyzed for data gaps caused by satellite-specific events such as, e.g., maneuvers and reboots of the Instrument Processing Unit (IPU). In case of larger gaps, the nominally one day long arcs are split into two or more shorter arcs over partial days. The minimum length of an arc, however, is set to three hours. To avoid any unwanted effects in the observations around such events, a margin of ten minutes is applied before and after data gaps when defining the final arcs.

\subsection{Background Models}

By definition, GRACE gravity field models represent geophysical signals caused by variations in the terrestrial water storage, mass loss in polar ice sheets and inland glacier systems, ocean mass variations, global isostatic adjustment and large earthquakes. Consequently, gravity variations caused by solid Earth and pole tides, atmosphere and ocean tides or short-term non-tidal atmospheric and oceanic mass variations are not supposed to be included in the gravity field solutions and are therefore taken into account during the data processing via background models. On the other hand, any error contained in the background models degrades the quality of the gravity field solutions, especially at low frequencies [24]. Thus, some of these background models have been updated for processing the GFZ RL06 time series (Table 1).

Table 1. Overview of background models used for GFZ RL05a and RL06 processing.

\begin{tabular}{ccc}
\hline Background Model & GFZ RL05a & GFZ RL06 \\
\hline Static a priori gravity field & $\begin{array}{c}\text { EIGEN-6C [25] (up to d/o 200) } \\
\text { Trend, annual and semi-annual } \\
\text { coefficients of EIGEN-6C } \\
\text { Time-variable a priori gravity field }\end{array}$ & $\begin{array}{c}\text { EIGEN-6C4 [26] (up to d/o 200) } \\
\text { GFZ RL05a (DDK1 smoothed, } \\
\text { up to d/o 50), only used } \\
\text { during data editing }\end{array}$ \\
Ocean tides & EOT11a [27] & FES2014 [28] \\
Atmospheric tides & Biancale \& Bode [29] & same as RL05a \\
Non-tidal atmospheric and & AOD1B RL05 [30] & AOD1B RL06 [31] \\
oceanic mass variations & Desai [32] & same as RL05a \\
Ocean pole tide & IERS2010 [33] & same as RL05a \\
Solid Earth and pole tides & JPL DE421 & JPL DE430 \\
3rd body ephemerides & &
\end{tabular}

Among the background models listed in Table 1, the choice of the Atmosphere and Ocean De-aliasing (AOD) and the ocean tide model has the most impact on the quality of the monthly GRACE solutions and hence their geophysical interpretation [24]. The AOD1B model is an official GRACE L1B product routinely generated at GFZ. Compared to its precursor AOD1B RL05, the most recent release AOD1B RL06 has higher temporal (3-hourly vs. 6-hourly) and spatial (maximum SH d/o 180 vs. 100) resolution. Further details are described by Dobslaw et al. [31], where also improvements in GRACE gravity field processing by means of variance reduction of K-band range-acceleration residuals are already reported when using AOD1B RL06 instead of RL05. Regarding ocean tides, similar improvements are observed when using FES2014 instead of EOT11a. Generally, the choice of the ocean tide model does not significantly affect the quality of individual monthly GRACE solutions, but regional deficiencies, especially at high latitudes, can become visible in GRACE time series analysis. In this context, Ray et al. [34] reported that the FES2014 model, used for GFZ RL06, shows improvements in most of the polar regions compared to its precursor and performs comparable to other state-of-the-art ocean tide models. 


\subsection{Processing Strategy}

The processing scheme of GRACE gravity field processing at GFZ consists of the following steps: (1) GPS data editing; (2) KRR data editing; (3) generation of a priori orbits; (4) generation of arc-wise NEQs; and (5) accumulation to and solving of monthly NEQs. For all previous GFZ GRACE releases from RL01 to RL05a, the strategy how these steps are performed is more or less identical and has been described by Schmidt [35]. For the current GFZ GRACE RL06 processing, the strategy has been considerably changed and is described in this section. An overview of the GFZ RL05a and RL06 processing strategies is given in Table 2.

Table 2. Overview of GFZ RL05a and RL06 processing strategies.

\begin{tabular}{|c|c|c|c|}
\hline & & GFZ RL05a & GFZ RL06 \\
\hline \multicolumn{4}{|l|}{ GPS data editing } \\
\hline Remarks & & GRACE-A \& -B jointly processed & GRACE-A \& -B independently processed \\
\hline \multicolumn{4}{|l|}{$\begin{array}{l}\text { Time-variable a priori } \\
\text { gravity field }\end{array}$} \\
\hline Observation weights & $\begin{array}{l}\sigma_{G P S p h a s e} \\
\sigma_{G P S c o d e} \\
\sigma_{K R R}\end{array}$ & $\begin{array}{c}0.7 \mathrm{~cm} \\
70.0 \mathrm{~cm} \\
50 \mu \mathrm{m} / \mathrm{s}\end{array}$ & $\begin{array}{c}0.3 \mathrm{~cm} \\
40.0 \mathrm{~cm} \\
\text { no KRR observations }\end{array}$ \\
\hline \multicolumn{4}{|l|}{ KRR data editing } \\
\hline \multirow{2}{*}{ Remarks } & & $\begin{array}{l}\text { further GPS data editing } \\
\text { still possible }\end{array}$ & $\begin{array}{l}\text { no further GPS } \\
\text { data editing }\end{array}$ \\
\hline & & $\begin{array}{l}\text { automated editing based } \\
\text { on } 8 \text {-sigma elimination }\end{array}$ & $\begin{array}{l}\text { no automated editing, instead } \\
\text { visual inspection of residuals }\end{array}$ \\
\hline $\begin{array}{l}\text { Time-variable a priori } \\
\text { gravity field }\end{array}$ & & yes & yes \\
\hline Observation weights & $\begin{array}{l}\sigma_{G P S \text { phase }} \\
\sigma_{\text {GPScode }} \\
\sigma_{\text {KRR }}\end{array}$ & $\begin{array}{c}0.7 \mathrm{~cm} \\
70.0 \mathrm{~cm} \\
0.1 \mu \mathrm{m} / \mathrm{s}\end{array}$ & $\begin{array}{c}0.3 \mathrm{~cm} \\
40.0 \mathrm{~cm} \\
0.3 \mu \mathrm{m} / \mathrm{s}\end{array}$ \\
\hline \multicolumn{4}{|c|}{ Generation of a priori orbits / generation of arc-wise NEQs } \\
\hline $\begin{array}{l}\text { Time-variable a priori } \\
\text { gravity field }\end{array}$ & & yes & no \\
\hline Observation weights & $\begin{array}{l}\sigma_{G P S p h a s e} \\
\sigma_{G P S c o d e} \\
\sigma_{K R R}\end{array}$ & $\begin{array}{c}0.7 \mathrm{~cm} \\
70.0 \mathrm{~cm} \\
0.1 \mu \mathrm{m} / \mathrm{s}\end{array}$ & $\begin{array}{c}\text { arc-wise based on residuals scaled by empirical factor of } 7 \\
\text { arc-wise based on residuals }\end{array}$ \\
\hline
\end{tabular}

Editing of GPS data is done by automated elimination during an iterative precise orbit determination (POD). The elimination is based both on an $n$-sigma criterion, with varying values for $n$ in the different iterations, and additionally an absolute threshold for the size of GPS residuals. The main difference in the GPS data editing step is that for RL06 the POD for both GRACE satellites is done completely independently from each other in contrast to RL05a, where down-weighted KRR observations were included and a common POD for GRACE-A and -B was applied. The goal for RL06 is to obtain best possible absolute orbit accuracy for each of the two spacecraft and thus to avoid that the elimination of GPS observations for one satellite is influenced by the other. Another difference concerns the empirical corrections for GPS phase center variations (PCV): For RL05a, a certain unvaried PCV correction based on one month (April 2008) of GPS residuals has been applied for the whole time series, whereas for RL06, monthly PCV corrections are computed from the corresponding monthly residuals. A novelty of RL06 is that also GPS code residual variation maps per month are computed and applied. In general, these empirical corrections are very stable over time, but they are significantly affected by systematic patterns whenever radio occultation measurements are activated onboard one of the GRACE satellites (Figure 1). Because activation and deactivation of these measurements has occurred several times throughout the GRACE mission (mostly related to satellite swap maneuvers), a monthly computation of these corrections has been chosen as the preferable option. Finally, the a priori weights for GPS phase and code observations have been changed from RL05a to RL06 to better reflect the actual level of the RMS of the corresponding residuals (see Table 2). 

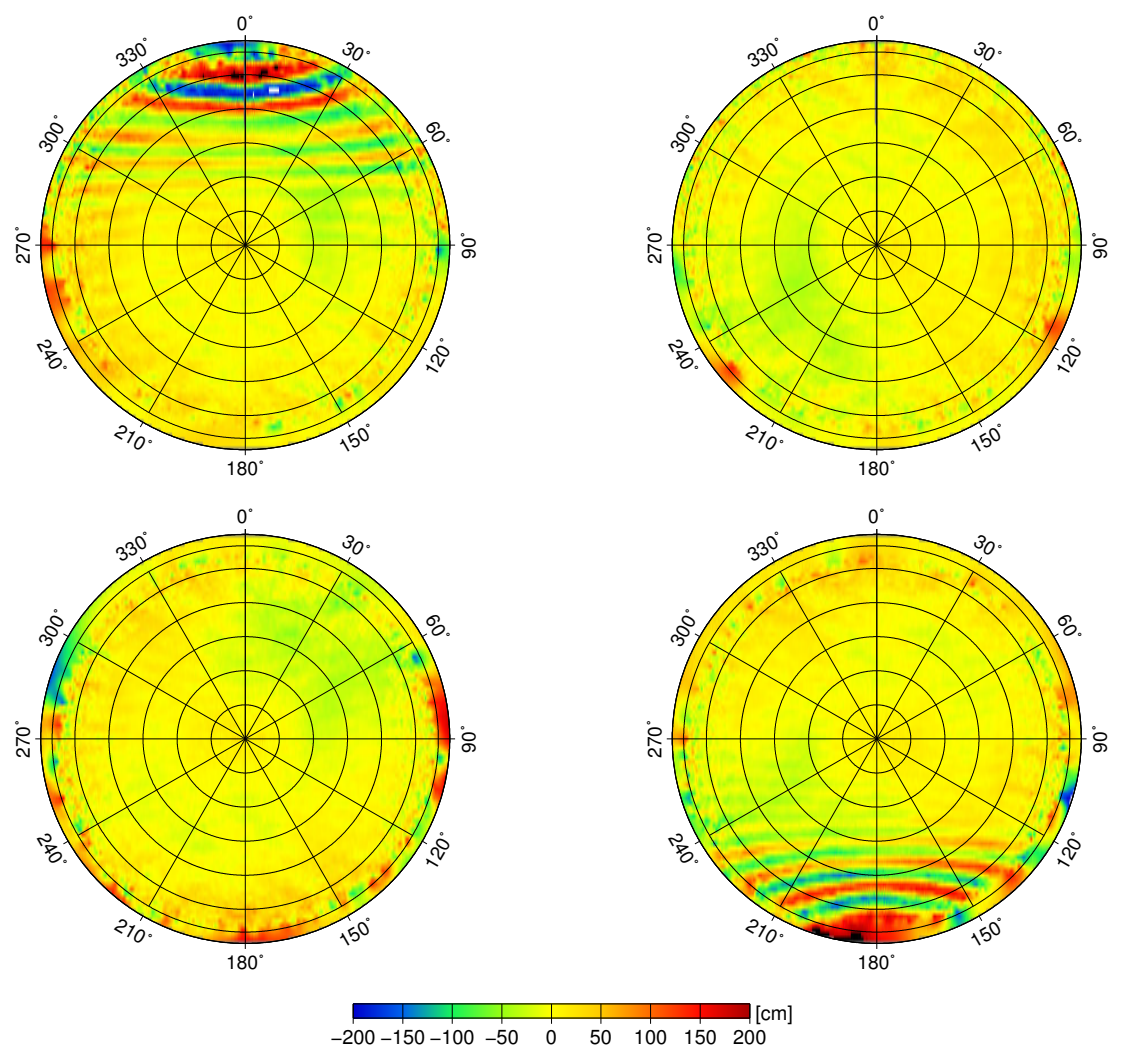

Figure 1. Code residual variation maps of GRACE-A (top) and GRACE-B (bottom) for June 2014 (left) and August 2014 (right). Radio occultation measurements on GRACE-A were activated in June 2014 and deactivated in August 2014 and vice versa on GRACE-B, after a satellite swap in July 2014.

For KRR data editing, a common POD for GRACE-A and -B is performed. In case of RL05a, where down-weighted KRR observations were already included in the previous step, the KRR weight was increased by setting the a priori standard deviation to $0.1 \mu \mathrm{m} / \mathrm{s}$, and elimination of KRR observations was automatically done based on an 8-sigma criterion. Further editing of GPS observations during this step was not explicitly turned off. In contrast, now for RL06 KRR observations are only introduced in this step with a slightly increased a priori standard deviation of $0.3 \mu \mathrm{m} / \mathrm{s}$ which better matches-as done similarly for GPS - the corresponding orbit fit RMS. No automated elimination at all is applied; instead, possible elimination of KRR observations-if needed-is based on visual inspection of the $\mathrm{KRR}$ residuals. Usually, observations are edited if the residuals exceed a threshold of $3 \mu \mathrm{m} / \mathrm{s}$, but this threshold is not fixed and other editing criteria such as anomalous behavior of the KRR residuals over a certain period of time within one arc might be applied. By modifying the KRR data editing as described, inadvertent elimination of observations over areas with large geophysical signals is avoided and about $1 \%$ more KRR observations (approx. 0.3 days accumulated over one month) remain and are used for gravity field determination in the case of RL06.

The purpose of generating the a priori orbit is to assure that convergence of a POD using the edited GPS and KRR observations and iterated orbit parameter estimates is reached after one iteration. If this condition is fulfilled, arc-wise NEQs are set up starting with the observations and initial parameters from the a priori orbit run. In case of RL05a, the observation weights from the previous data editing steps remained unchanged, whereas for RL06 individual arc-wise weighting for GPS and KRR observations has been introduced. Arc-wise a priori standard deviations are based on the RMS of the corresponding residuals after the KRR editing run: In case of KRR, they are equal to the RMS values; for GPS, the RMS values are multiplied by an empirical factor of 7 . This intentional down-weighting of GPS observations relative to the K-band observations is necessary to obtain better gravity field solutions and is also done similarly by other processing centers (see, e.g., $[10,16])$. 
Another modification from RL05a to RL06 regards the time-variable a priori gravity field which in case of RL05a was used as background model also during these two last-mentioned processing steps. This required restoring of the monthly mean of these a priori fields to the estimated monthly GRACE solution to provide users a Level-2 gravity field product which contains the full time-variable signal as expected per definition. For RL06, the time-variable gravity field background model is only used during the data editing steps, where background modeling is desired to be as realistic as possible, but not during the steps where gravity field determination takes place. Thus, any possible bias that might be introduced by applying a remove-restore procedure as described for RL05a is avoided for RL06.

\subsection{Parametrization}

In conjunction with the processing strategy, the orbit and instrument parametrization has also been significantly changed from GFZ RL05a to RL06 (see Table 3).

In RL05a processing, empirical accelerations were only set up and estimated during the GPS data editing step. In the subsequent steps, these parameters were completely removed, and empirical K-band parameters were introduced [35]. For RL06, empirical accelerations are set up more frequently (once per orbital revolution) and remain as parameters throughout all processing steps to assure a consistent parametrization from GPS editing until gravity field estimation. To avoid that these parameters absorb too much gravity field signal, an a priori standard deviation of $1 \mathrm{E}-8 \mathrm{~m} / \mathrm{s}^{2}$ is applied as constraint. In contrast to RL05a, no K-band parameters at all are set up in RL06. Internal tests have shown that the additional estimation of K-band parameters does not significantly impact the estimated gravity field solution, but leads to a degradation in orbit accuracy.

Further modifications from RL05a to RL06 affect the ACC instrument parameters. Regarding the ACC biases, their number has been decreased. Now for RL06, usually three biases per arc are estimated in along-track and radial direction (at the beginning, middle, and end of the arc), and nine in cross-track direction (at the beginning and end, and equally spaced in between). The number of biases can become less in case the arc length is shorter than $24 \mathrm{~h}$, as the minimum spacing between two biases is set to three hours. Between the epochs where biases are estimated, the bias is modeled as a natural cubic spline function (RL05a: linear interpolation). Regarding ACC scale factors, one per arc and direction is estimated in case of RL06. This is a lesson learned from RL05a processing, where for most of the time series the scales were fixed to one, which turned out to be not optimal especially in the later years of the GRACE mission. Therefore, this was modified within RL05a to estimating 3-hourly scales, which helped to improve the quality of the RL05a solutions, but on the other hand tends to over-parameterize the gravity field estimation process. Another notable difference between RL05a and RL06 is the parametrization during the "GRACE single ACC" period: Whereas for RL05a the parametrization was the same as for the rest of the GRACE mission, a fully populated scale factor matrix is estimated per arc in case of RL06. This has been proposed first by Klinger and Mayer-Gürr [36] and is applied to the complete ITSG-Grace2016/2018 time series, as well as to other recent releases such as the CSR RL06 [10] and JPL RL06 [11] time series. For GFZ RL06, the additional six parameters, i.e., the off-diagonal elements of the scale factor matrix, are constrained with an a priori standard deviation of 1E-3 since otherwise, the inversion of the NEQ system becomes unstable and in many cases would fail.

In summary, the total number of orbit and instrument parameters described above has decreased for RL06 compared to most of the RL05a solutions, and is nearly identical compared to the RL05a solutions with modified ACC parametrization. Moreover, as already mentioned, the parametrization is now consistent during all processing steps. It has to be mentioned as well that there are other parameters not listed in Table 3, namely GPS receiver clock offsets (2880 per 1-day arc and satellite) and GPS phase ambiguities (approx. 400 per 1-day arc and satellite). However, these two parameter groups are pre-eliminated before gravity field estimation and there are no differences in their treatment between RL05a and RL06 processing. 
Finally, regarding the main parameters of interest, i.e., the gravity field parameters, the maximum SH d/o estimated was slightly increased from 90 (RL05a) to 96 (RL06). New with GFZ RL06, an independently estimated GRACE time series only up to d/o 60 is provided additionally. These two decisions have been made jointly within the GRACE SDS to ensure better consistency between the three SDS time series than it was the case with RL05. Furthermore, both KRR and GPS observations contribute to the full spectrum of the monthly gravity field estimates in GFZ RL06, whereas in GFZ RL05a the contribution of GPS was limited to SH d/o 80.

Table 3. Number and properties of GFZ RL05a and RL06 orbit and instrument parameters (numbers are per arc representative for the nominal arc length of $24 \mathrm{~h}$ ).

\begin{tabular}{|c|c|c|c|c|}
\hline & \multicolumn{2}{|c|}{ GFZ RL05a } & \multicolumn{2}{|c|}{ GFZ RL06 } \\
\hline & GPS editing step & subsequent steps & GPS editing step & subsequent steps \\
\hline Orbital elements & \multicolumn{4}{|c|}{ 6/6 (GRACE-A/GRACE-B) } \\
\hline \multirow[t]{2}{*}{ Empirical accel. } & $20 / 20$ & none & \multicolumn{2}{|r|}{$64 / 64$} \\
\hline & \multicolumn{4}{|c|}{$\cos /$ sin coefficients of $1 /$ rev periodical model } \\
\hline \multirow[t]{2}{*}{ Details } & every $4.8 \mathrm{~h}$ in TN & - & \multicolumn{2}{|c|}{$1 / \mathrm{rev}$ in $\mathrm{TN}$} \\
\hline & no constraint & - & \multicolumn{2}{|c|}{ constraint: $\sigma=1 \mathrm{E}-8 \mathrm{~m} / \mathrm{s}^{2}$} \\
\hline K-band param. & none & 48 & \multicolumn{2}{|r|}{ none } \\
\hline Details & - & $\begin{array}{l}\text { range-rate bias \& } \\
\text { drift every } 90 \text { min; } \\
\text { cos/sin coeff. of range } \\
\text { bias every } 180 \mathrm{~min}\end{array}$ & \multicolumn{2}{|r|}{-} \\
\hline \multirow{2}{*}{ ACC param. } & \multicolumn{2}{|c|}{$75 / 75^{(1)}$} & \multicolumn{2}{|c|}{$18 / 18^{(3)}$} \\
\hline & \multicolumn{2}{|c|}{$54 / 54^{(2)}$} & $18 / 18^{(4)}$ & $24 / 24(4)$ \\
\hline \multirow{2}{*}{ Details } & \multicolumn{2}{|c|}{$\begin{array}{l}\text { 1-hourly biases in RTN; } \\
\text { scale factors fixed to } 1^{(1)}\end{array}$} & \multicolumn{2}{|c|}{$\begin{array}{l}3 \text { biases per arc in RT; } 9 \text { in N } \\
1 \text { scale factor per arc in RTN }\end{array}$} \\
\hline & \multicolumn{2}{|c|}{$\begin{array}{l}\text { 3-hourly biases in RTN; } \\
\text { 3-hourly scale factors in } \mathrm{RTN}^{(2)}\end{array}$} & & $\begin{array}{l}6 \text { off-diagonal elements } \\
\text { of scale factor matrix; } \\
\text { constraint: } \sigma=1 \mathrm{E}-3 \text { (4) }\end{array}$ \\
\hline
\end{tabular}

\subsection{Orbit Quality}

The quality of the GRACE orbits determined prior to gravity field estimation was not in the focus during GFZ RL05a processing. For GFZ RL06, the modifications in processing strategy and parametrization are motivated not only to obtain improved gravity fields, but also orbits of high quality.

A first indication that this goal is reached is given by GPS phase and code residuals of the GPS editing runs which are extremely stable during the whole mission with arc-wise RMS values of about $3 \mathrm{~mm}$ and $40 \mathrm{~cm}$, respectively (for the "GRACE single ACC" period, only a slight increase is observed). In contrast to RL05a, the size of GPS residuals does not increase at all when adding KRR observations in the subsequent processing steps which can be attributed to the consistent parametrization.

Another independent orbit validation during RL06 processing is routinely done by means of satellite laser ranging (SLR) observations from ground stations to the GRACE satellites, provided by the International Laser Ranging Service (ILRS). Coarse outliers in the SLR observations are eliminated by a $20 \mathrm{~cm}$ threshold. Mean values and standard deviations of GRACE-A and -B SLR residuals per year are shown in Figure 2 for all available stations and a subset of high-quality stations. The definition of such a subset has been outlined by Arnold et al. [37] and the same 12 stations are used here for better comparability. These high-quality stations contribute between $50 \%$ and $75 \%$ of all available observations. It can be seen that the standard deviations are in the range of $20 \mathrm{~mm}$ to $25 \mathrm{~mm}$ for all stations and about $15 \mathrm{~mm}$ for the high-quality stations. For the year 2010, the standard deviations 
for GRACE-A are $24.5 \mathrm{~mm}$ and $13.7 \mathrm{~mm}$, respectively, which agrees very well with values of $24.4 \mathrm{~mm}$ and $12.3 \mathrm{~mm}$, respectively, reported in [37]. As for the GPS residuals, the values are the same whether only GPS observations are used or KRR observations are added, and are also very similar for both GRACE satellites. Increased standard deviations, in particular for recent years, are observed for the a priori orbits which can be explained by the fact that these orbits are determined without a time-variable gravity background model and GPS observations are down-weighted. The mean values of GRACE-A and $-\mathrm{B}$ as are also very consistent, independent of the processing step or whether all or the high-quality stations are evaluated. They are mostly in the range of $-10 \mathrm{~mm}$ to $-15 \mathrm{~mm}$ which is relatively large. However, this is not necessarily due to the orbit quality, but may also be caused by incorrect values for the GPS phase center offset (PCO) of the GRACE GPS navigation antennas. For GFZ RL06, PCOs relative to the antenna reference point provided by Montenbruck et al. [38] are used. A geometrical offset (distance between the satellites' center of mass and the antenna reference point) of $-444 \mathrm{~mm}$ is added-only for the z-component in the SRF-resulting in a total L3 PCO in z-direction of $-391.7 \mathrm{~mm}$. This value is approx. $22 \mathrm{~mm}$ larger than the corresponding value derived from the official GRACE L1B vector offset product for the GPS main antenna (VGN1B, see [21]) which might at least partly explain the relatively large negative offsets reported here.

Overall, the quality of the GFZ GRACE RL06 orbits is satisfyingly well confirming that the processing changes relative to GFZ RL05a have been a step into the right direction.

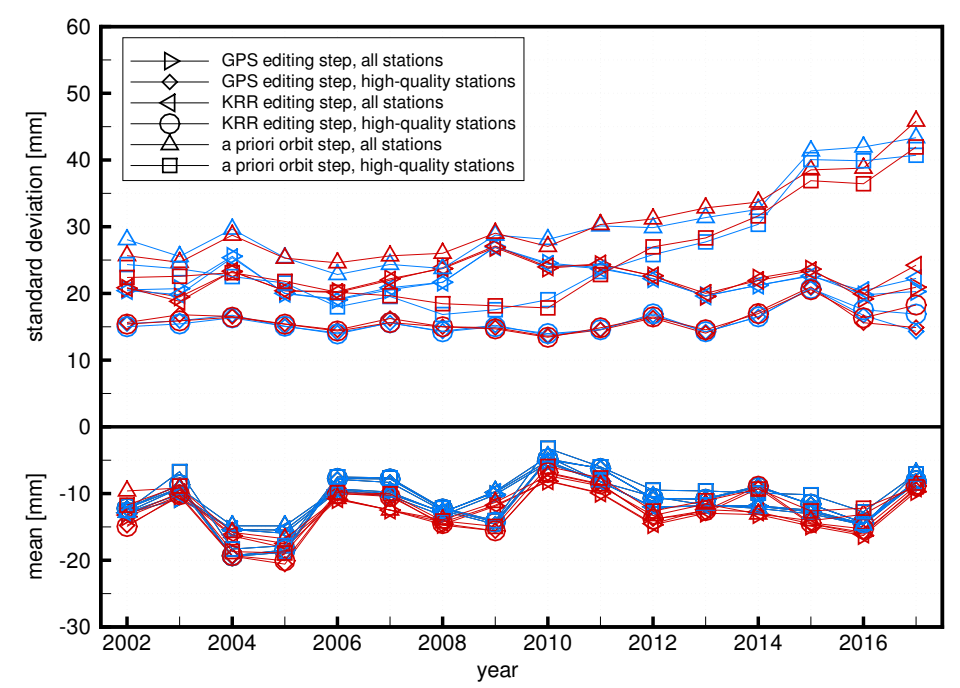

Figure 2. Mean and standard deviation per year of GRACE-A (blue) and -B (red) SLR residuals during the different GRACE processing steps for all available stations and a subset of high-quality stations.

\section{Results}

GFZ GRACE RL06 gravity field results are analyzed and discussed in comparison to GFZ's RL05a GRACE time series in the following subsections. Most of the results shown are relative to a climatology model (individually derived for each time series) which has been estimated as follows: The dominating signal content of the time series is approximated by fitting a proper parameter model coefficient-wise to the monthly solutions. Here, eight parameters describing the constant and linear part as well as periodic sine and cosine amplitudes for annual, semi-annual and 161-days (GRACE aliasing period for the ocean tide S2) periods are used. Furthermore, the formal errors of the monthly SH coefficients are used as a priori information to weight each individual monthly coefficient when estimating the climatology. Months with short repeat cycles (i.e., solutions which were regularized in RL05a) as well as the seven "GRACE single ACC" solutions are excluded. 


\subsection{Formal and Empirical Errors}

In this subsection formal and empirical errors of the GFZ RL06 time series are analyzed in the spectral domain and compared to GFZ RL05a. The formal errors are the standard deviations of the gravity field parameters estimated in the least-squares adjustment process, i.e., the square root of the diagonal of the gravity field parameter part of the variance-covariance matrices. In principle, these errors should give a good indication of the real errors of the estimated parameters. However, as variance-covariance information of all the input data is insufficiently (observations) or not all (background models) applied, the formal errors are typically too optimistic.

Another quantification of the errors of such a gravity field time series are empirically derived values. Here, residuals regarding the climatology described above are defined as empirical errors of the time series.

Figure 3 shows the RMS over the whole time series of the empirical and formal errors for RL05a and RL06. The main differences between empirical and formal errors can be seen in the very low $\mathrm{SH}$ degrees and around so-called resonance orders. Due to residual signals in the very low degrees, which are not covered by the eight parameters, the empirical errors show much higher values than the formal ones here. Around the resonance orders, which are integer multiples of approximately 15, it is well known that GRACE errors are larger due to systematic effects from temporal aliasing caused by background model errors. This effect is not very well represented in the formal errors.

(a)

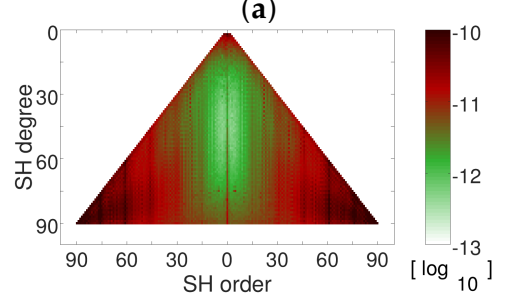

(c)

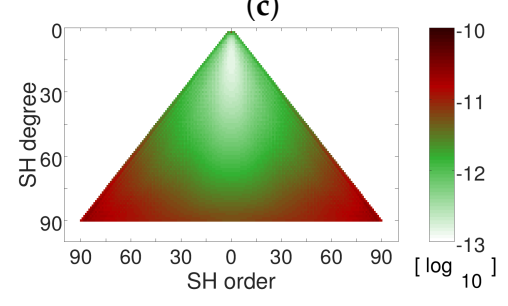

(e)

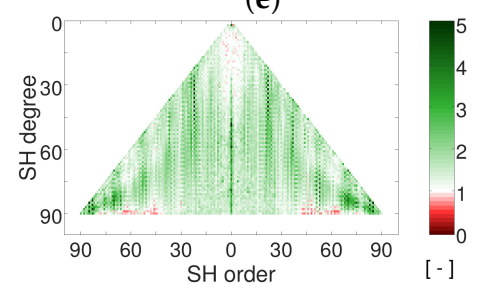

(b)

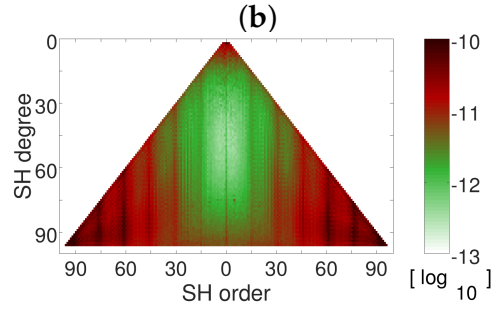

(d)

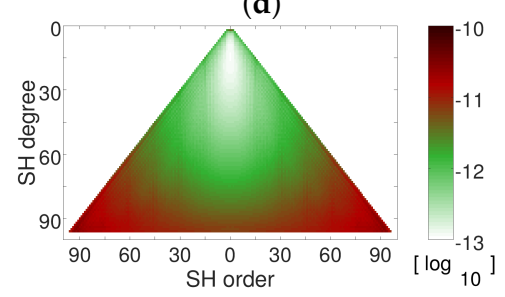

(f)

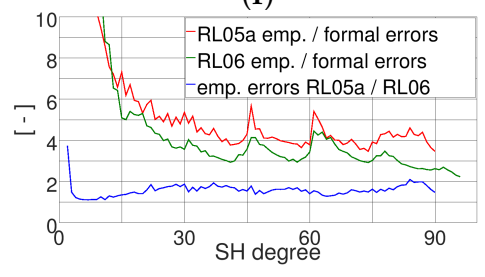

Figure 3. (a-d) SH spectra of empirical error RMS for RL05a (a) and RL06 (b); and of formal error RMS for RL05a (c) and RL06 (d); (e) Ratio of SH spectra of empirical error RMS "RL05a/RL06"; (f) SH degree amplitudes of the ratio of empirical error RMS "RL05a/RL06" (blue), and the ratios "empirical/formal error RMS" for RL05a (red), and RL06 (green).

Compared to RL05a (Figure 3a,c), Figure 3b,d reveal smaller empirical errors and more realistic formal errors for RL06. This becomes even more clear when looking at the ratio of the empirical error 
RMS values between RL05a and RL06 (Figure 3e) which is $>1$ for nearly all coefficients and also when plotted as amplitudes per SH degree (Figure 3f). Also, the degree amplitudes of the ratio between empirical and formal errors indicate that the GFZ RL06 formal errors are more realistic as smaller variations than for GFZ RL05a are visible and the curve is closer to the value of one.

\subsection{Degree Amplitudes}

Difference degree amplitudes relative to climatology are shown in Figure 4. The spread of monthly degree amplitudes is less for RL06 than for RL05a which illustrates that RL06 is a more homogeneous time series. Significant differences between the RL05a and RL06 median degree amplitudes are already visible at approx. SH degree 15, and almost all monthly RL06 degree amplitude curves are well below the median RL05a curve (or vice versa) for medium and high degrees indicating a notably improved signal-to-noise ratio for RL06. When only looking at the "GRACE single ACC" period, large improvements from RL05a to RL06 are achieved according to the corresponding median degree amplitudes. These improvements are not only present for medium and high degrees, but also for the very low degrees. However, the quality of the "GRACE single ACC" solutions is still significantly worse than for the rest of the GRACE mission also in case of RL06.
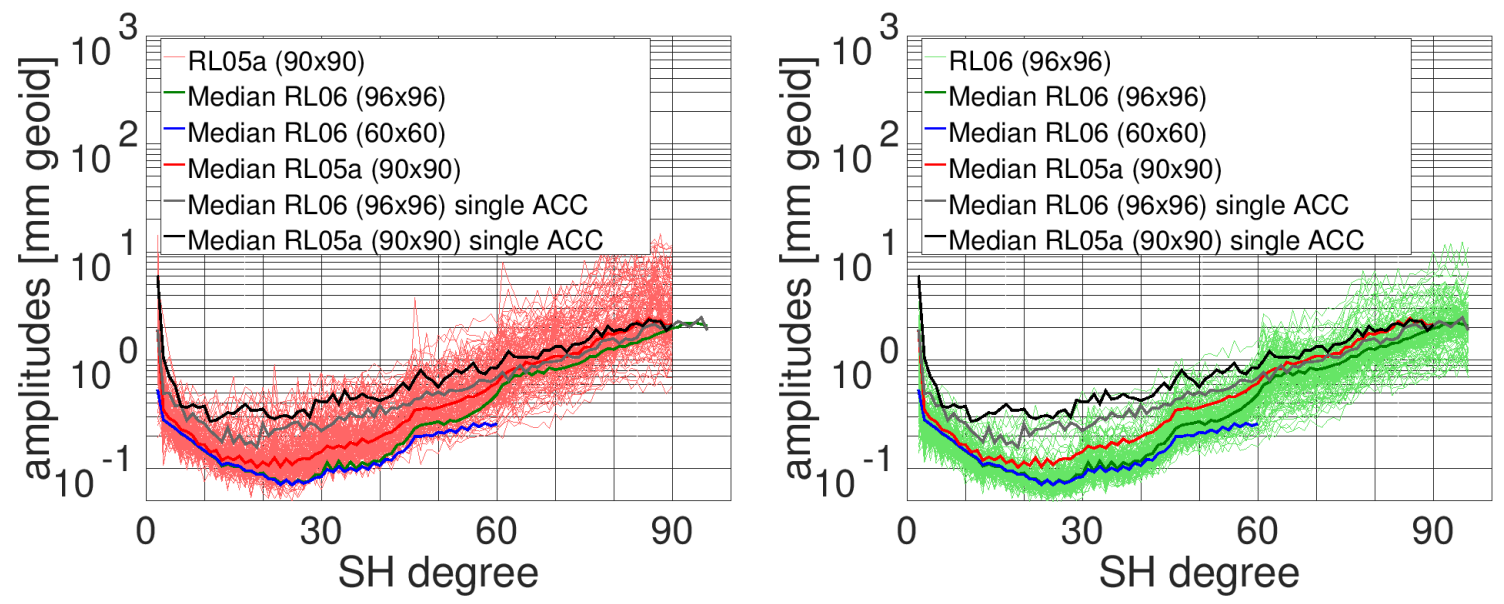

Figure 4. Degree amplitudes relative to a climatology model for GFZ RL05a (left) and GFZ RL06 (right); thin lines represent monthly solutions (without "GRACE single ACC" solutions and those regularized in RL05a), and bold lines represent the median curves (the same curves are shown in both plots) for RL05a (red), RL06 (96 × 96, green), RL06 $(60 \times 60$, blue), and the “GRACE single ACC" months only for RL05a (black) and RL06 $(96 \times 96$, grey).

\subsection{RMS of Residuals in the Spatial Domain}

To assess the quality of the GFZ RL06 time series in the spatial domain, monthly residual SH coefficients relative to climatology are converted to gridded mass anomalies in terms of equivalent water height (EWH). To reduce the impact of spatially correlated noise, the solutions are de-correlated and smoothed by applying the non-isotropic DDK filter [39]. Then, RMS values of the time series per grid point are calculated and shown in Figure 5. For the period until August 2016, i.e., without the "GRACE single ACC" months, a clear reduction of RMS variability for RL06 has been achieved (Figure 5a,b). Geophysical signals over continental areas, where they are much larger than over the oceans, are less superimposed by the typical GRACE striping pattern and thus better detectable. Variability over the oceans is generally expected to be rather small and is therefore often interpreted as upper error bound for monthly global GRACE gravity field models. Latitude-dependent weighted RMS (wRMS) values over the oceans decrease from $6.8 \mathrm{~cm}$ (RL05a) to $4.0 \mathrm{~cm}$ (RL06, 41\% relative improvement) when DDK5 filtered, and from $3.4 \mathrm{~cm}$ (RL05a) to $2.1 \mathrm{~cm}$ (RL06, 38\% relative improvement) when DDK3 filtered. For the "GRACE single ACC" period, 
Figure 5c shows DDK3 filtered RMS variability to allow a direct comparison with the period before, but it becomes obvious that much stronger decorrelation and smoothing would be required here to extract geophysical signals. Nevertheless, the corresponding wRMS values over ocean decrease again significantly from $9.5 \mathrm{~cm}$ (RL05a) to $6.1 \mathrm{~cm}$ (RL06, 36\% relative improvement).

(a)
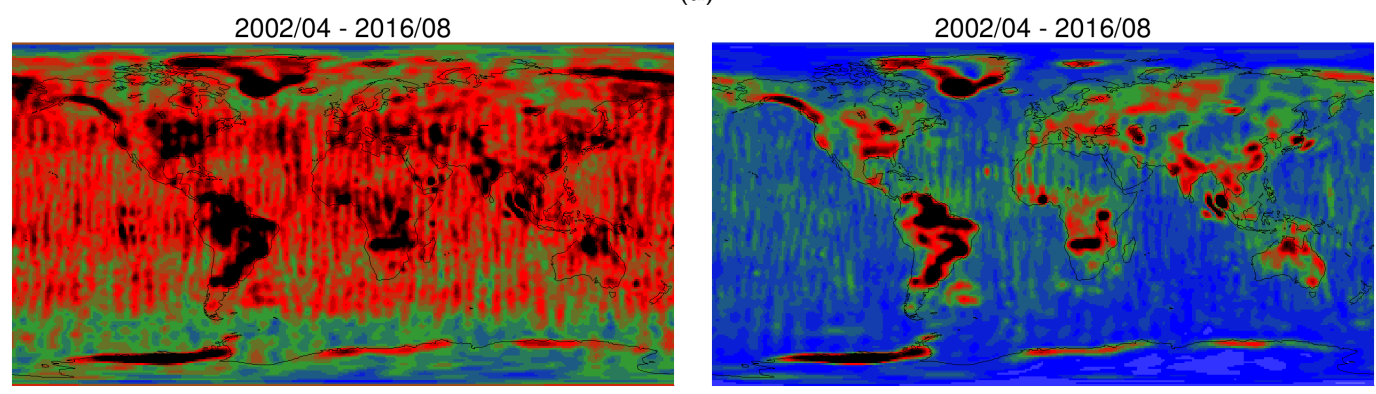

(b)
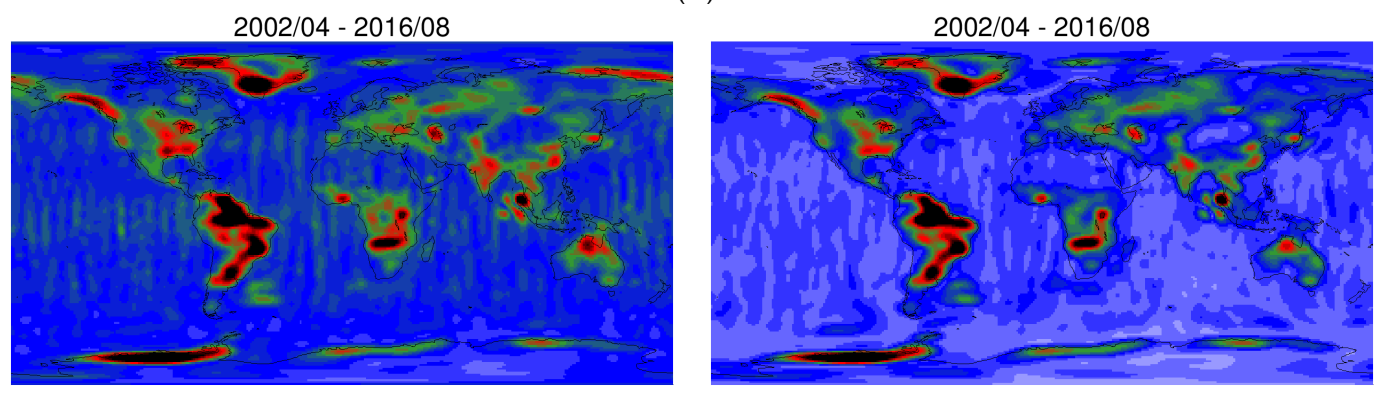

(c)
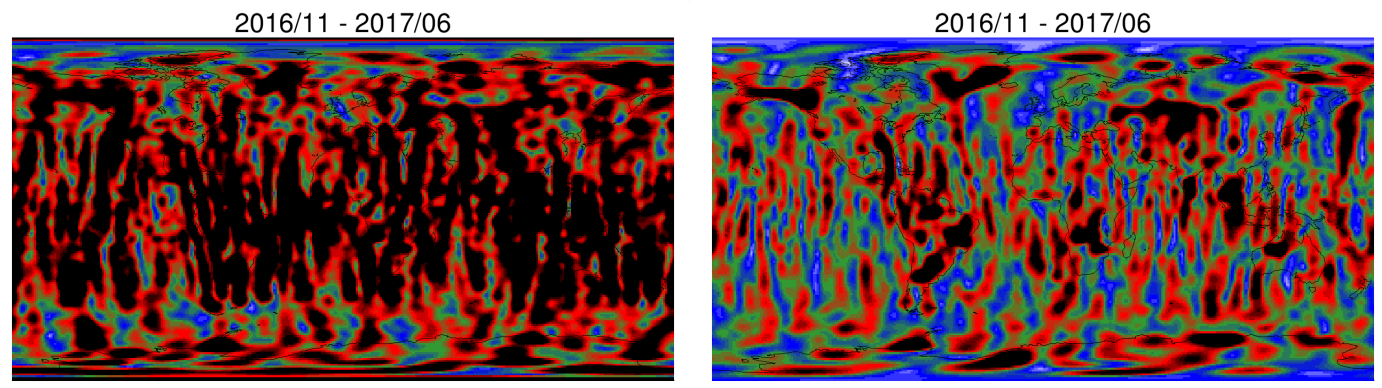

0

2

$4 \mathrm{~cm}^{6}$

8

Figure 5. RMS of the time series of residuals $(\mathrm{cm} \mathrm{EWH})$ relative to a climatology model (without months regularized in RL05a) for GFZ RL05a (left) and GFZ RL06 (right); the following different cases are shown: period from 2002/04 through 2016/08, DDK5 filtered (a) and DDK3 filtered (b); and "GRACE single ACC" period, DDK3 filtered (c).

Monthly wRMS values over the oceans for the complete GRACE time series (DDK5 filtered) are shown in Figure 6. Again, it becomes visible that GFZ RL06 is a clear improvement over RL05a in terms of noise reduction and homogeneity. Some months where RL06, particularly for the $96 \times 96$ time series, exhibits larger wRMS values than RL05a can be attributed to short period repeat orbit cycles (the most harmful repeat orbits during the GRACE mission are: 61/4 around September 2004, 46/3 around May 2012, 77/5 around December 2013, 31/2 around February 2015). RL05a solutions for these months were regularized which is not the case anymore for RL06 as the additionally provided RL06 $60 \times 60$ time series, which is less sensitive to these short period repeat orbits, might be analyzed instead. Apart from the repeat cycles just mentioned before, the wRMS values of the RL06 $96 \times 96$ and 
$60 \times 60$ time series are mostly almost identical. Periods where these values are notably larger are again related to less harmful repeat cycles such as the long-lasting 107/7 repeat orbit around December 2009. Finally, also Figure 6 shows that the "GRACE single ACC" months are of much less quality than the rest of the time series. At least, the RL06 solution for May 2017 is now of comparable quality (it must be noted that for this solution GRACE-B ACC data is actually available and used).

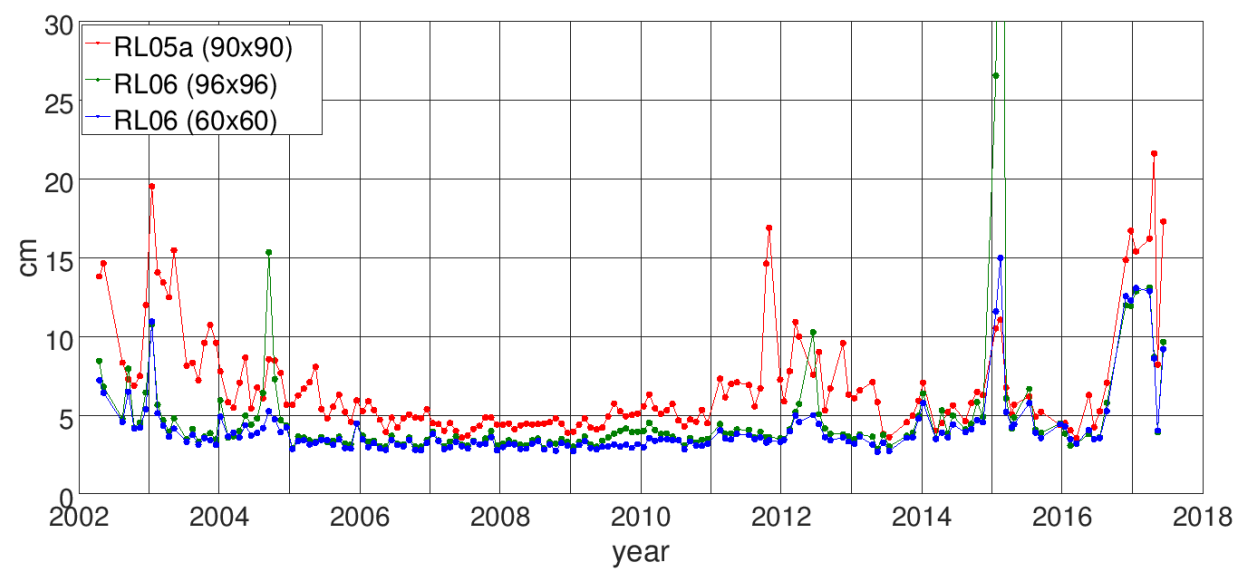

Figure 6. wRMS over the oceans (cm EWH) of DDK5 filtered residuals relative to a climatology model for the complete GFZ RL05a (red), GFZ RL06 $(96 \times 96$, green), and GFZ RL06 $(60 \times 60$, blue) time series.

\subsection{Low Degree Harmonics}

In this subsection, time series of selected low degree $\mathrm{SH}$ coefficients are analyzed, starting with $\mathrm{C}_{20}$. This coefficient is known to be poorly estimated from GRACE (see, e.g., [40]), and it is common practice to replace it, e.g., with estimates derived from SLR observations to geodetic satellites. Despite the fact that the GFZ GRACE RL06 $\mathrm{C}_{20}$ values have significantly improved compared to GFZ RL05a (Figure 7a), a replacement of $C_{20}$ is still recommended for RL06 before using the time series for geophysical interpretation. Available SLR-based replacement time series which are consistent with RL06 standards are, e.g., GRACE Technical Note TN-11 generated by CSR [41], or a similar time series provided by GFZ [42] which is also shown in Figure 7a.

Two other coefficients requiring special attention are $C_{21}$ and $S_{21}$. When analyzing surface mass variations from the GRACE SDS RL05 time series, Wahr et al. [43] recommended corrections to these coefficients to account for effects of the applied mean pole model. Since all three SDS RL06 time series including GFZ RL06 are processed based on a linear mean pole model which is conform to the updated IERS2010 mean pole convention (http:/ / iers-conventions.obspm.fr/chapter7.php), this recommendation is not applicable anymore to these reprocessed time series. Looking at the GFZ RL06 $\mathrm{C}_{21}$ time series in comparison to GFZ RL05a (Figure 7b), however, one can see an anomalous behavior during the "GRACE single ACC" period. Although already the RL05a time series shows larger amplitudes in that period, this is even more pronounced in RL06. A similar behavior is visible also for $S_{21}$ (Figure 7c). The reason for these anomalies in $C_{21}$ and $S_{21}$ is not yet fully understood and subject to further investigation. As it is clearly correlated with the use of ACC data transplant, a possible explanation would be that it is due to inaccurate modeling of surface forces, potentially in conjunction with an inappropriate parametrization. First experiments at GFZ combining GRACE and SLR on NEQ level have revealed promising results and might lead to a replacement time series, similar to $C_{20}$, to overcome these deficiencies in the near future. It should be mentioned here that a GRACE+SLR combination would not be a novelty as, e.g., the GRACE solutions provided by the CNES/GRGS group are in fact already based on a combination with SLR [15]. 
(a)

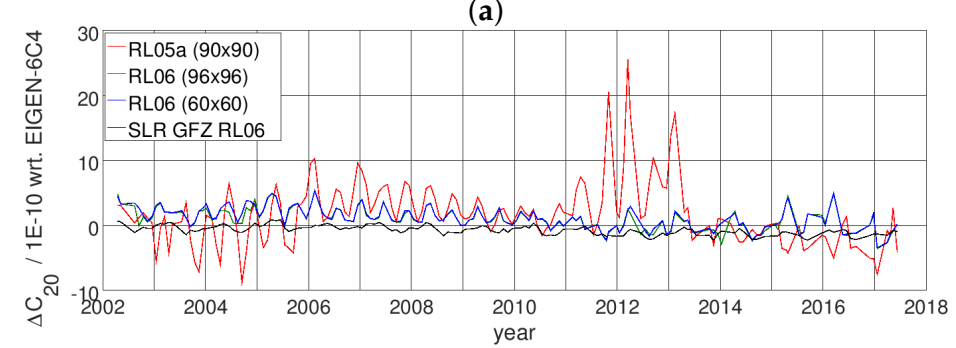

(b)

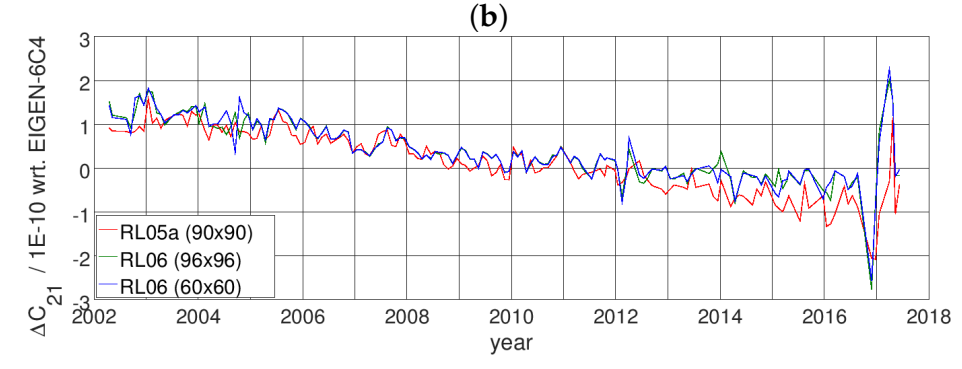

(c)

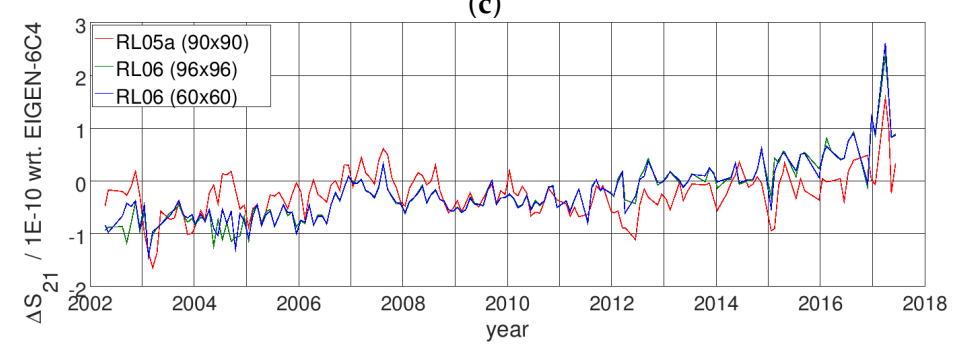

Figure 7. Time series of $\mathrm{SH}$ coefficients $\mathrm{C}_{20}(\mathbf{a}) ; \mathrm{C}_{21}(\mathbf{b})$; and $\mathrm{S}_{21}(\mathbf{c})$; each plot shows values of GFZ RL05a (red), GFZ RL06 (96 × 96, green), and GFZ RL06 $\left(60 \times 60\right.$, blue); for $C_{20}$, the SLR-based time series König et al. [42] is shown additionally (black).

\section{External Validation}

Due to the uniqueness of GRACE Level-2 products as observable for studies of Earth surface mass transport and climate change, it is nontrivial to validate them against independent data or models, and thus to reliably assess the quality of different GRACE time series in terms of signal content rather than only assessing their internal noise level. In the following subsections, two methods to evaluate the quality of the GFZ RL06 and RL05a time series by external data are presented.

\subsection{OBP Validation}

First, the GFZ GRACE RL06 and RL05a solutions are independently validated by comparing them with ocean bottom pressure (OBP) in situ observations.

The OBP database used here was initially compiled by Macrander et al. [44] and consists of 167 stations which are irregularly scattered over the oceans covering the time period from 2002 through 2010 with observation lengths for individual stations of up to eight years. The station data are preprocessed as outlined by Poropat et al. [7] to obtain time series of OBP observations with removed trends, tidal variability, outliers, and discontinuities at certain dates related to instrument issues including maintenance and battery replacement.

For the OBP validation, the GFZ RL06 and RL05a Level-2 solutions are post-processed as follows: The $\mathrm{C}_{20}$ coefficients are replaced with GRACE Technical Notes TN-11 and TN-07 [40], for RL06 
and RL05a, respectively, the effects of glacial isostatic adjustment are corrected by subtracting the model by A et al. [45], co-seismic signatures from three megathrust earthquakes are removed with estimates from the GOCO06s model [46], and approximated degree-1 coefficients according to Bergmann-Wolf et al. [47] are added. The DDK filter is applied to de-correlate the solutions: DDK4 is used for the long-term trend component, whereas DDK2 is used for the annual and semi-annual components and for the remaining residual monthly signals. Please note that for five monthly solutions with particularly poor signal-to-noise ratio, the DDK1 filter is used. Finally, the monthly GAD background model [48] including atmospheric surface pressure and non-tidal OBP is added back.

These post-processed GRACE data are evaluated at the locations of the OBP in situ recorders. Regionally different linear trends, specifically caused by changing sea level, are removed. Since GRACE data do not represent a point-measurement, but an average over a large area, areas of coherent OBP variability are identified and the GRACE OBP data are averaged over these areas [49]. The selection of these areas follows [7].

To compare GRACE and in situ OBP variations at the OBP in situ sites, relative explained variances (defined as $\left.\sigma_{r}^{2}=\left(\sigma_{\text {in situ OBP }}^{2}-\sigma_{\text {in situ OBP - GRACE OBP }}^{2}\right) / \sigma_{\text {in situ OBP }}^{2}\right)$ and correlation coefficients are calculated from both time series. Generally, positive relative explained variances are observed for about $35 \%$ of the OBP in situ stations (Figure $8 a$ ), indicating that GRACE-derived and observed OBP variations correspond rather poorly in many regions. However, improvements in relative explained variance for GFZ RL06 compared to GFZ RL05a become visible in most regions (Figure 8c). The same conclusion can be drawn for the correlations, where a slight increase for GFZ RL06 can be seen as well again in most regions (Figure 8d). Generally, correlation coefficients between GRACE and in situ OBP are within the range of 0.1 to 0.7 for most of the stations (Figure $8 \mathrm{~b}$ ); the corresponding 25th, 50th, and 75 th percentiles are $0.21,0.34$, and 0.54 , respectively. Overall, a slightly better performance of GFZ RL06 over GFZ RL05a in explaining OBP variability over wide regions is achieved.

(a)

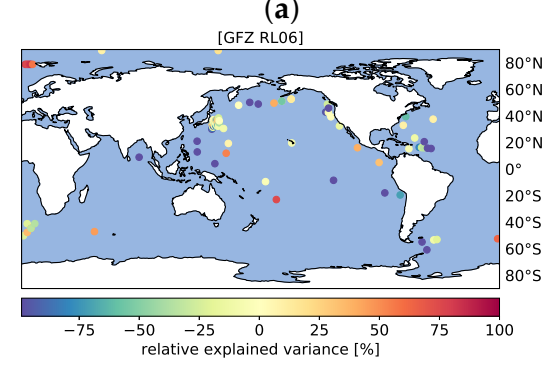

(c)

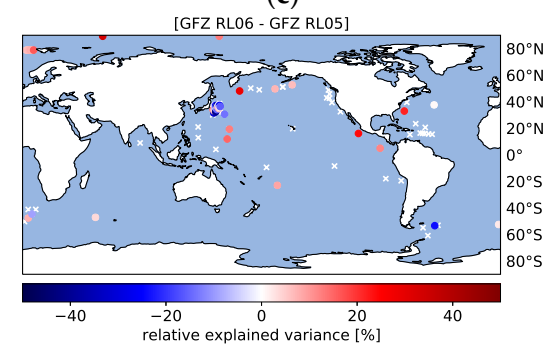

(b)

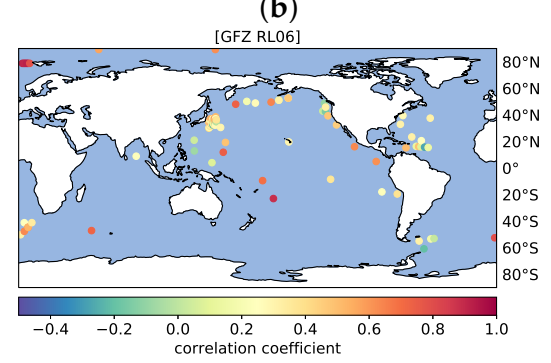

(d)

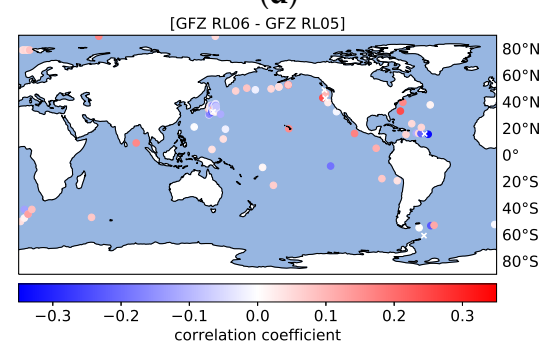

Figure 8. (a) Relative explained variances $\sigma_{r}^{2}$ at in situ OBP stations for GFZ RL06; (b) Correlation coefficients between in situ OBP and GRACE OBP for GFZ RL06; (c) Difference of relative explained variances for GFZ RL06 and GFZ RL05a; (d) Difference of correlation coefficients for GFZ RL06 and GFZ RL05a. For (c) and (d), red colors indicate improvements of GFZ RL06 over GFZ RL05a; stations with relative explained variances or correlation coefficients $<0$ for both RL06 and RL05a are marked with white crosses. 


\subsection{GOCE Orbit Tests}

As another independent validation, orbits of ESA's Gravity field and steady-state Ocean Circulation Explorer (GOCE) mission are used to compare the quality of monthly GRACE gravity solutions. The GOCE satellite [50], in orbit from March 2009 until November 2013, had a very low orbital altitude of about $255 \mathrm{~km}$ and thus shows a rather high sensitivity to the Earth's gravity field.

For these orbit tests, dynamic orbits are fitted to GOCE kinematic 3D orbit positions which are taken as observations (i.e., not directly the GPS tracking data). These kinematic orbits (Precise Science Orbits) have been generated at AIUB [51] and are provided within the GOCE High Level Processing Facility. For this study, GOCE orbit tests have been carried out for four months (November and December 2009, October and November 2010), each consisting of 30 individual GOCE arcs with a length of 1.25 days. The ocean tide model used here is FES2014 [28] to SH d/o 100. The reference system and gravitational force modeling is done applying the IERS 2010 [33] conventions. GOCE common mode accelerations are used during orbit computation instead of non-gravitational force models. The scale factors of the common mode accelerations cannot be accurately estimated per arc due to the drag-free control system which has compensated most of the signal and are therefore fixed to one [52]. This value is accurate within 3\%, as demonstrated by Visser and van den IJssel [53]. The GOCE gradiometer works best in the measurement bandwidth of 10 to $200 \mathrm{~s}$ [54], and consequently the common mode accelerations include an instrumental bias. Therefore, three common mode acceleration biases per arc are estimated, one in each direction, in addition to the initial state vector.

For each month, two versions of orbit fits are computed which are identical except for the background gravity field model: The first version uses the corresponding GFZ RL06 monthly solutions, the second one uses the GFZ RL05a solutions instead, both up to SH d/o 90. Due to the high gravitational sensitivity of GOCE, the monthly GRACE models are filled up with SH coefficients from the long-term static GOCE model GO_CONS_GCF_2_DIR_R6 [55] up to d/o 240 to achieve reasonable orbit fits at the level of few centimeters.

The results of the GOCE orbit tests are listed in Table 4. When using GFZ RL06 instead of GFZ RL05a as background model, the RMS values of the orbit fits are clearly reduced for all four months, with relative improvements of GFZ RL06 over GFZ RL05a ranging from $12 \%$ to $25 \%$. The significant differences in the orbit fits prove that such kind of orbit validation tests are an appropriate tool for the validation of monthly GRACE gravity field solutions. For future validation purposes, it is planned to extend the orbit validation to the complete GOCE mission period and to investigate whether orbits of other Low Earth Orbiting satellites such as, e.g., CHAMP and Swarm can be used as well.

Table 4. RMS of orbit fits [cm] for the time-variable GFZ RL05a and RL06 gravity field models and (only for reference) for the static model GO_CONS_GCF_2_DIR_R6. RMS values are based on 3D residuals and represent mean values of the 30 individual arcs within a particular month.

\begin{tabular}{ccccc}
\hline \multirow{2}{*}{ Gravity Field Model } & \multicolumn{4}{c}{ Month } \\
\cline { 2 - 5 } & $\mathbf{2 0 0 9 / 1 1}$ & $\mathbf{2 0 0 9 / 1 2}$ & $\mathbf{2 0 1 0 / 1 0}$ & $\mathbf{2 0 1 0 / 1 1}$ \\
\hline GFZ RL05a & 8.39 & 9.14 & 7.53 & 7.40 \\
GFZ RL06 & 7.39 & 6.84 & 6.24 & 6.21 \\
GO_CONS_GCF_2_DIR_R6 & 3.56 & 3.37 & 3.82 & 3.76 \\
\hline
\end{tabular}

\section{Conclusions}

GFZ has reprocessed an improved monthly gravity field time series for the complete GRACE mission consisting of 163 gravity field models (Level-2 products) in the period from April 2002 through June 2017. This GFZ GRACE RL06 time series incorporates a reprocessed in-house GPS constellation (orbits and clocks), reprocessed Level-1B K-band ranging, star camera and accelerometer (ACC) transplant observations (L1B RL03 dataset provided by JPL), updated background models 
for tidal (FES2014) and non-tidal (AOD1B RL06) mass variations, and a considerably modified processing strategy including a different parametrization with (for most months) even less parameters compared to the precursor GFZ RL05a. Key features of the new RL06 processing strategy are a strict separation of GPS and K-band data editing, manual instead of automated sigma-based K-band data editing, and omittance of a time-variable gravity background model during the gravity field estimation step. Main differences in RL06 parametrization compared to RL05a are consistently estimated parameters throughout all processing steps, less ACC parameters (biases and scale factors), and -exclusively for the last months where ACC transplant data has to be used for GRACE-B ("GRACE single ACC" period)-the estimation of a fully populated ACC scale factor matrix. Independent validation by satellite laser ranging (SLR) observations reveals a satisfying quality of the GRACE orbits prior to gravity field adjustment with standard deviations of SLR residuals $<20 \mathrm{~mm}$ for selected high-quality stations.

With the new GFZ RL06 time series significant improvements have been achieved: The noise is considerably reduced and, consequently, geophysical signals are better detectable and can be analyzed at smaller spatial scales. Relative improvements over GFZ RL05a in terms of residual RMS variability are about $40 \%$ for both DDK3 and DDK5 filtered solutions. Furthermore, the complete time series is more homogeneous. Although the GFZ RL06 formal errors are still too optimistic for most of the gravity field coefficients, they exhibit a more realistic behavior, and also empirical errors in terms of residuals relative to a climatology model are smaller than for GFZ RL05a. The quality of the gravity fields within the "GRACE single ACC" period is clearly worse compared to the rest of the time series, but relative to RL05a, the RL06 solutions are also significantly improved here. Special attention needs to be paid to the $\mathrm{C}_{21}$ and $\mathrm{S}_{21}$ coefficients showing unrealistic amplitudes during that period. A combined GRACE+SLR replacement time series for these coefficients might help to mitigate this issue, as first investigations at GFZ have indicated. Regarding the $C_{20}$ coefficient, known to be poorly estimated from GRACE, it is still advised to replace the values by external time series, e.g., derived from SLR. Such a time series that is consistently processed with GRACE RL06 standards, is also provided by GFZ [42].

External validation by means of comparison with in situ ocean bottom pressure observations as well as orbit tests with the GOCE satellite confirm that improvements have been achieved with GFZ RL06 over RL05a, enabling thus a better understanding of phenomena in the Earth system related to climate change. To put the relative improvement from RL05a to RL06 in context with the relative improvements between all GFZ GRACE releases since RL01, Figure 9 shows gravity field anomalies for all previous GFZ GRACE releases exemplarily for the month August 2003. The corresponding relative improvements in terms of wRMS over ocean are as follows: RL01 to RL02: 14\%, RL02 to RL03: 24\%, RL03 to RL04: 4\%, RL04 to RL05a: 0\%, RL05a to RL06: 41\%. This is another clear indication of the remarkable improvements achieved with the GFZ RL06 reprocessing and also depicts that even after more than 15 years of the first instrument data release a substantial gain in the quality of monthly GRACE gravity field products is possible thanks to reprocessing efforts regarding Level-1 and Level-2 products, but also improved background models and enhanced processing strategies. Hence, reprocessing of a GRACE RL07 time series is already planned, for which a final release of Level-1 products will be available. Apart from using these new Level-1 data and possible background model updates, the specific focus at GFZ for RL07-or other likely upcoming releases-will be on the reported $C_{21} / S_{21}$ issue, as well as on a further reduction of noise as achieved by other groups (see, e.g., [14]). Whereas modification or fine tuning of the parametrization is always a promising option in view of improvements, in particular the application of an improved stochastic modeling of errors in observations and background models is envisaged.

A comparison between GFZ RL06 and recently published GRACE time series by other processing centers is not the purpose of this work; however, such comparisons were already done in several other studies: Göttl et al. [56] report an increased consistency of the SDS (CSR, JPL, GFZ) RL06 and ITSG-Grace2018 solutions compared to the SDS RL05 and ITSG-Grace2016 solutions. Kvas et al. [14] investigated the signal content of the SDS RL06 and ITSG-Grace2018 solutions by evaluating river 
basin averages and conclude that all four solutions exhibit the same signal content. Adhikari et al. [57] calculated sea-level fingerprints using the SDS RL06 time series and find that differences between these three solutions are within 1-sigma uncertainties.

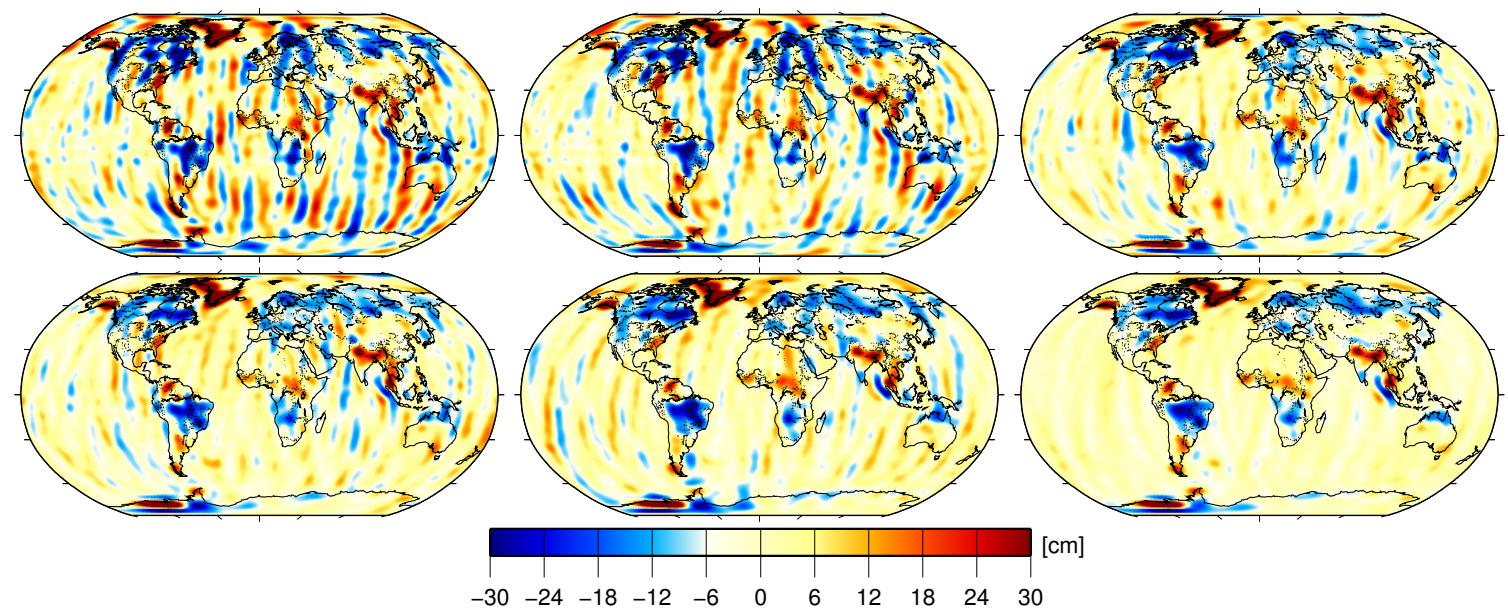

Figure 9. Gravity field anomalies in terms of cm EWH (DDK3 filtered) for the month 2003/08 for all GFZ GRACE releases so far: RL01 (top left), RL02 (top middle), RL03 (top right), RL04 (bottom left), RL05a (bottom middle), and RL06 (bottom right).

The GFZ GRACE RL06 monthly gravity field time series consists of fully unconstrained spherical harmonic ( $\mathrm{SH}$ ) Level-2 products, i.e., no regularization at all is applied, and is provided in two versions as agreed upon within the GRACE SDS: (1) up to SH degree and order 96; and (2) up to SH degree and order 60. GFZ GRACE RL06 is available at GFZ's Information System and Data Center (ISDC) archive (https://isdc.gfz-potsdam.de/grace-isdc/) along with related documentation ([12]; Release Notes for GFZ RL06 Level-2 products (ftp:/ /isdcftp.gfz-potsdam.de/ grace/DOCUMENTS/RELEASE_NOTES/GRACE_GFZ_L2_Release_Notes_for_RL06.pdf); GRACE Level-2 User Handbook (ftp:/ /isdcftp.gfz-potsdam.de/grace/DOCUMENTS/Level-2/GRACE_L2_ Gravity_Field_Product_User_Handbook_v4.0.pdf)).

GFZ GRACE RL06 processing standards and background models are also used for the initial GFZ GRACE-FO Level-2 product release [58]. Moreover, GFZ GRACE/GRACE-FO RL06 Level-2 products are the basis for GFZ's web portal GravIS (Gravity Information Service, http:/ / gravis.gfz-potsdam.de), jointly developed with the Alfred-Wegener-Institut and TU Dresden, where dedicated Level-3 products for hydrological, oceanic and polar ice-sheet applications are visualized and offered for download. Finally, the GFZ GRACE RL06 time series contributes to the newly established International Combination Service for Time-variable Gravity Fields (COST-G), a product center of the International Gravity Field Service (IGFS).

Author Contributions: Conceptualization, C.D.; Processing of GRACE orbits and gravity fields, C.D.; Processing of GPS orbits, A.R.; Software, C.D., M.M., G.M., K.H.N. and O.A.; Validation of results, C.D., M.M., H.D., R.S. and C.F.; Writing-Original Draft Preparation, C.D.; Writing-Review and Editing, M.M., F.F., H.D., R.S. and C.F.; Visualization, C.D., M.M. and R.S.; Supervision, F.F., H.D. and R.K.; Project Administration, F.F.; Funding Acquisition, F.F., H.D. and R.K.

Funding: This research was partly funded by the German Ministry for Education and Research (BMBF) with FKZ 03F0654A, and by the German Research Foundation (DFG) within Research Group 2736 NEROGRAV (New Refined Observations of Climate Change from Spaceborne Gravity Missions).

Acknowledgments: We would like to thank the German Space Operations Center (GSOC) of the German Aerospace Center (DLR) for providing continuously and nearly $100 \%$ of the raw telemetry data of the twin GRACE satellites. Valuable comments by four anonymous reviewers helped to improve the manuscript and are highly appreciated. 
Conflicts of Interest: The authors declare no conflict of interest. The funders had no role in the design of the study; in the collection, analyses, or interpretation of data; in the writing of the manuscript, or in the decision to publish the results.

\section{References}

1. Rodell, M.; Famiglietti, J.S.; Wiese, D.N.; Reager, J.T.; Beaudoing, H.K.; Landerer, F.W.; Lo, M.H. Emerging trends in global freshwater availability. Nature 2018, 557, 651-659. [CrossRef] [PubMed]

2. Kusche, J.; Eicker, A.; Forootan, E.; Springer, A.; Longuevergne, L. Mapping probabilities of extreme continental water storage changes from space gravimetry. Geophys. Res. Lett. 2016, 43, 8026-8034. [CrossRef]

3. Sasgen, I.; Konrad, H.; Ivins, E.R.; Van den Broeke, M.R.; Bamber, J.L.; Martinec, Z.; Klemann, V. Antarctic ice-mass balance 2003 to 2012: Regional reanalysis of GRACE satellite gravimetry measurements with improved estimate of glacial-isostatic adjustment based on GPS uplift rates. Cryosphere 2013, 7, 1499-1512. [CrossRef]

4. Wouters, B.; Gardner, A.S.; Moholdt, G. Global Glacier Mass Loss During the GRACE Satellite Mission (2002-2016). Front. Earth Sci. 2019, 7, 96. [CrossRef]

5. Reager, J.T.; Gardner, A.S.; Famiglietti, J.S.; Wiese, D.N.; Eicker, A.; Lo, M.H. A decade of sea level rise slowed by climate-driven hydrology. Science 2016, 351, 699-703. [CrossRef] [PubMed]

6. Rietbroek, R.; Brunnabend, S.E.; Kusche, J.; Schröter, J; Dahle, C. Revisiting the contemporary sea-level budget on global and regional scales. Proc. Natl. Acad. Sci. USA 2016, 113, 1504-1509. [CrossRef] [PubMed]

7. Poropat, L.; Dobslaw, H.; Zhang, L.; Macrander, A.; Boebel, O.; Thomas, M. Time variations in ocean bottom pressure from a few hours to many years: In situ data, numerical models, and GRACE satellite gravimetry. J. Geophys. Res. Ocean 2018, 123, 5612-5623. [CrossRef]

8. Landerer, F.W.; Wiese, D.N.; Bentel, K.; Boening, C.; Watkins, M.M. North Atlantic meridional overturning circulation variations from GRACE ocean bottom pressure anomalies. Geophys. Res. Lett. 2015, 42, 8114-8121. [CrossRef]

9. Tapley, B.D.; Watkins, M.M.; Flechtner, F.; Reigber, C.; Bettadpur, S.; Rodell, M.; Sasgen, I.; Famiglietti, J.S.; Landerer, F.W.; Chambers, D.P.; et al. Contributions of GRACE to understanding climate change. Nat. Clim. Chang. 2019, 9, 358-369. [CrossRef]

10. Bettadpur, S. UTCSR Level-2 Processing Standards Document (For Level-2 Product Release 0006) (Rev. 5.0, April 18, 2018). GRACE Publication 327-742. 2018. Available online: ftp:/ / isdcftp.gfz-potsdam. de/grace/DOCUMENTS/Level-2/ (accessed on 10 September 2019).

11. Yuan, D.N. JPL Level-2 Processing Standards Document For Level-2 Product Release 06 (Rev. 6.0, June 1, 2018). GRACE Publication 327-744. 2018. Available online: ftp:/ /isdcftp.gfz-potsdam.de/grace/DOCUMENTS/ Level-2/ (accessed on 10 September 2019).

12. Dahle, C.; Flechtner, F.; Murböck, M.; Michalak, G.; Neumayer, K.; Abrykosov, O.; Reinhold, A.; König, R. GRACE 327-743 (Gravity Recovery and Climate Experiment): GFZ Level-2 Processing Standards Document for Level-2 Product Release 06 (Rev. 1.0, October 26, 2018); Scientific Technical Report STR - Data, 18/04; GFZ German Research Centre for Geosciences: Potsdam, Germany, 2018. [CrossRef]

13. Kornfeld, R.P.; Arnold, B.W.; Gross, M.A.; Dahya, N.T.; Klipstein, W.M.; Gath, P.F.; Bettadpur, S. GRACE-FO: The Gravity Recovery and Climate Experiment Follow-On Mission. J. Spacecr. Rocket. 2019, 56, 931-951. [CrossRef]

14. Kvas, A.; Behzadpour, S.; Ellmer, M.; Klinger, B.; Strasser, S.; Zehentner, N.; Mayer-Gürr, T. ITSG-Grace2018: Overview and Evaluation of a New GRACE-Only Gravity Field Time Series. J. Geophys. Res. Solid Earth 2019, 124. [CrossRef]

15. Lemoine, J.M.; Bourgogne, S.; Biancale, R.; Bruinsma, S. RL04 monthly gravity field solutions from CNES/GRGS. In Proceedings of the the GRACE/GRACE-FO Science Team Meeting, Potsdam, Germany, 9-11 October 2018.

16. Meyer, U.; Jäggi, A.; Jean, Y.; Beutler, G. AIUB-RL02: An improved time-series of monthly gravity fields from GRACE data. Geophys. J. Int. 2016, 205, 1196-1207. [CrossRef] 
17. Chen, Q.; Shen, Y.; Chen, W.; Francis, O.; Zhang, X.; Chen, Q.; Li W.; Chen, T. An optimized short-arc approach: Methodology and application to develop refined time series of Tongji-Grace2018 GRACE monthly solutions. J. Geophys. Res. Solid Earth 2019, 124, 6010-6038. [CrossRef]

18. Dahle, C.; Flechtner, F.; König, R.; Michalak, G.; Neumayer, K.; Gruber, C.; König, D. GFZ RL05: An Improved Time-Series of Monthly GRACE Gravity Field Solutions. In Observation of the System Earth from Space - CHAMP, GRACE, GOCE and Future Missions. Advanced Technologies in Earth Sciences; Flechtner, F., Sneeuw, N., Schuh, W., Eds.; Springer: Berlin/Heidelberg, Germany, 2014; pp. 29-39, ISBN 978-3-642-32134-4. [CrossRef]

19. Reigber, C. Gravity field recovery from satellite tracking data. In Theory of Satellite Geodesy and Gravity Field Determination; Lecture Notes in Earth Sciences; Sanso, F., Rummel, R., Eds.; Springer: Berlin/Heidelberg, Germany, 1989; Volume 25, pp. 197-234, ISBN 3-540-51528-3.

20. König, D. A Terrestrial Reference Frame realised on the observation level using a GPS-LEO satellite constellation. J. Geod. 2018, 92, 1299-1312. [CrossRef]

21. Case, K.; Kruizinga, G.; Wu, S. GRACE Level 1B Data Product User Handbook (Rev. 1.3). JPL Publication D-22027. 2010. Available online: ftp:/ /isdcftp.gfz-potsdam.de/grace/DOCUMENTS/Level-1/ (accessed on 10 September 2019).

22. GRACE. GRACE Level 1B JPL Release 3.0; Data Publication; PO.DAAC: CA, USA, 2018. [CrossRef]

23. Bandikova, T.; McCullough, C.; Kruizinga, G.L.; Save, H.; Christophe, B. GRACE accelerometer data transplant. Adv. Space Res. 2019, 64, 623-644. [CrossRef]

24. Flechtner, F.; Neumayer, K.H.; Dahle, C.; Dobslaw, H.; Fagiolini, E.; Raimondo, J.C., Güntner, A. What Can be Expected from the GRACE-FO Laser Ranging Interferometer for Earth Science Applications? Surv. Geophys. 2016, 37, 453-470. [CrossRef]

25. Förste, C.; Bruinsma, S.; Shako, R.; Marty, J.C.; Flechtner, F.; Abrykosov, O.; Dahle, C.; Lemoine, J.M.; Neumayer, K.H.; Biancale, R.; et al. EIGEN-6-A New Combined Global Gravity Field Model Including GOCE Data from the Collaboration of GFZ-Potsdam and GRGS-Toulouse; Geophysical Research Abstracts Vol. 13, EGU2011-3242-2; EGU General Assembly: Vienna, Austria, 2011.

26. Förste, C.; Bruinsma, S.; Abrykosov, O.; Lemoine, J.M.; Marty, J.C.; Flechtner, F.; Balmino, G.; Barthelmes, F.; Biancale, R. EIGEN-6C4 The Latest Combined Global Gravity Field Model Including GOCE Data Up to Degree and Order 2190 of GFZ Potsdam and GRGS Toulouse; Data Publication; GFZ Data Services: Potsdam, Germany, 2014. [CrossRef]

27. Savcenko, R.; Bosch, W. EOT11a_Empirical Ocean Tide Model from Multi-Mission Satellite Altimetry; Report No. 89; Deutsches Geodätisches Forschungsinstitut: München, Germany, 2012.

28. Carrere, L.; Lyard, F.; Cancet, M.; Guillot, A.; Picot, N. FES2014, a new tidal model-Validation results and perspectives for improvements. In Proceedings of the ESA Living Planet Symposium 2016, Prague, Czech Republic, 9-13 May 2016.

29. Biancale, R.; Bode, A. Mean Annual and Seasonal Atmospheric Tide Models Based on 3-hourly and 6-hourly ECMWF Surface Pressure Data; Scientific Technical Report STR, 06/01; GFZ German Research Centre for Geosciences: Potsdam, Germany, 2006. [CrossRef]

30. Dobslaw, H.; Flechtner, F.; Bergmann-Wolf, I.; Dahle, C.; Dill, R.; Esselborn, S.; Sasgen, I.; Thomas, M. Simulating high-frequency atmosphere-ocean mass variability for de-aliasing of satellite gravity observations: AOD1B RL05. J. Geophys. Res. Ocean 2013, 118, 3704-3711. [CrossRef]

31. Dobslaw, H.; Bergmann-Wolf, I.; Dill, R.; Poropat, L.; Thomas, M.; Dahle, C.; Esselborn, S.; König, R.; Flechtner, F. A new high-resolution model of non-tidal atmosphere and ocean mass variability for de-aliasing of satellite gravity observations: AOD1B RL06. Geophys. J. Int. 2017, 211, 263-269. [CrossRef]

32. Desai, S.D. Observing the pole tide with satellite altimetry. J. Geophys. Res. 2002, 107, 3186. [CrossRef]

33. Petit, G.; Luzum, B. IERS Conventions (2010); IERS Technical Note No. 36; Verlag des Bundesamts für Kartographie und Geodäsie: Frankfurt am Main, Germany, 2010; p. 179, ISBN 3-89888-989-6.

34. Ray, R.D.; Loomis, B.D.; Luthcke, S.B.; Rachlin, K.E. Tests of ocean-tide models by analysis of satellite-to-satellite range measurements: An update. Geophys. J. Int. 2019, 217, 1174-1178. [CrossRef]

35. Schmidt, R. Zur Bestimmung des cm-Geoids und Dessen Zeitlicher Variationen mit GRACE. Scientific Technical Report STR, 07/04. Ph.D. Thesis, GFZ German Research Centre for Geosciences, Potsdam, Germany, 2007. [CrossRef] 
36. Klinger, B.; Mayer-Gürr, T. The role of accelerometer data calibration within GRACE gravity field recovery: Results from ITSG-Grace2016. Adv. Space Res. 2016, 58, 1597-1609. [CrossRef]

37. Arnold, D.; Montenbruck, O.; Hackel, S.; Sosnica, K. Satellite laser ranging to low Earth orbiters: Orbit and network validation. J. Geod. 2018. [CrossRef]

38. Montenbruck, O.; Garcia-Fernandez, M.; Yoon, Y.; Schön, S.; Jäggi, A. Antenna phase center calibration for precise positioning of LEO satellites. GPS Solut. 2009, 13:23. [CrossRef]

39. Kusche, J.; Schmidt, R.; Petrovic, S.; Rietbroek, R. Decorrelated GRACE time-variable gravity solutions by GFZ, and their validation using a hydrological model. J. Geod. 2009, 83, 903-913. [CrossRef]

40. Cheng, M.K.; Ries, J.C. The unexpected signal in GRACE estimates of C20. J. Geod. 2017, 91, 897-914. [CrossRef]

41. Cheng, M.K.; Ries, J.C. Monthly estimates of C20 from 5 SLR Satellites Based on GRACE RL06 Models. GRACE Technical Note TN-11. Available online: ftp://isdcftp.gfz-potsdam.de/grace/DOCUMENTS/ TECHNICAL_NOTES/TN-11_C20_SLR_RL06.txt (accessed on 10 September 2019).

42. König, R.; Schreiner, P.; Dahle, C. Monthly Estimates of C $(2,0)$ Generated by GFZ from SLR Satellites Based on GFZ GRACE/GRACE-FO RL06 Background Models. V. 1.0; Data Publication; GFZ Data Services: Potsdam, Germany, 2019. [CrossRef]

43. Wahr, J.; Nerem, R. S.; Bettadpur, S.V. The pole tide and its effect on GRACE time-variable gravity measurements: Implications for estimates of surface mass variations. J. Geophys. Res.: Solid Earth 2015, 120, 4597-4615. [CrossRef]

44. Macrander, A.; Böning, C.; Boebel, O.; Schröter, J. Validation of GRACE Gravity Fields by In-Situ Data of Ocean Bottom Pressure. In System Earth via Geodetic-Geophysical Space Techniques. Advanced Technologies in Earth Sciences; Flechtner, F., Gruber, T., Güntner, A., Mandea, M., Rothacher, M., Schöne, T., Wickert, J., Eds.; Springer: Berlin/Heidelberg, Germany, 2010; pp. 169-185, ISBN 978-3-642-10227-1. [CrossRef]

45. A, G.; Wahr, J.; Zhong, S. Computations of the viscoelastic response of a 3-D compressible Earth to surface loading: An application to glacial isostatic adjustment in Antarctica and Canada. Geophys. J. Int. 2013, 192, 557-572. [CrossRef]

46. Kvas, A.; Mayer-Gürr, T.; Krauss, S.; Brockmann, J.M.; Schubert, T.; Schuh, W.D.; Pail, R.; Gruber, T.; Jäggi, A.; Meyer, U. The Satellite-Only Gravity Field Model GOCO06s; Data Publication; GFZ Data Services: Potsdam, Germany, 2019. [CrossRef]

47. Bergmann-Wolf, I.; Zhang, L.; Dobslaw, H. Global eustatic sea-level variations for the approximation of geocenter motion from GRACE. J. Geod. Sci. 2014, 4, 37-48. [CrossRef]

48. Dobslaw, H.; Dill, R.; Dahle, C. GRACE Geopotential GAD Coefficients GFZ RL06. V. 6.0; Data Publication; GFZ Data Services: Potsdam, Germany, 2018. [CrossRef]

49. Böning, C.; Timmermann, R.; Macrander, A.; Schröter, J. A pattern-filtering method for the determination of ocean bottom pressure anomalies from GRACE solutions. Geophys. Res. Lett. 2008, 35, L18611. [CrossRef]

50. Drinkwater, M.; Haagmans, R.; Muzi, D.; Popescu, A.; Floberghagen, R.; Kern, M.; Fehringer, M. The GOCE gravity mission: ESA's first core explorer. In Proceedings of the 3rd International GOCE User Workshop, Frascati, Italy, 6-9 November 2006; ESA SP-627, pp. 1-8, ISBN 92-9092-938-3.

51. Bock, H.; Jäggi, A.; Beutler, G.; Meyer, U. GOCE: Precise orbit determination for the entire mission. J. Geod. 2014, 88, 1047-1060. [CrossRef]

52. Gruber, T.; Visser, P.N.A.M.; Ackermann, C.; Hosse, M. Validation of GOCE gravity field models by means of orbit residuals and geoid comparisons. J. Geod. 2011, 85, 845-860. [CrossRef]

53. Visser, P.N.A.M.; van den Ijssel, J. Calibration and validation of individual GOCE accelerometers by precise orbit determination. J. Geod. 2016; 90, 1-13. [CrossRef]

54. Pail, R.; Bruinsma, S.; Migliaccio, F.; Förste, C.; Goiginger, H.; Schuh, W.D.; Höck, E.; Reguzzoni, M.; Brockmann, J.M.; Abrikosov, O.; et al. First GOCE gravity field models derived by three different approaches. J. Geod. 2011, 85, 819. [CrossRef]

55. Förste, C.; Abrykosov, O.; Bruinsma, S.; Dahle, C.; König, R.; Lemoine, J.M. ESA's Release 6 GOCE Gravity Field Model by Means of the Direct Approach Based on Improved Filtering of the Reprocessed Gradients of the Entire Mission; Data Publication; GFZ Data Services: Potsdam, Germany, 2019. [CrossRef]

56. Göttl, F.; Schmidt, M.; Seitz, F. Mass-related excitation of polar motion: An assessment of the new RL06 GRACE gravity field models. Earth Planets Space 2018, 70, 195. [CrossRef] 
57. Adhikari, S.; Ivins, E.R.; Frederikse, T.; Landerer, F. W.; Caron, L. Sea-level fingerprints emergent from GRACE mission data. Earth Syst. Sci. Data 2019, 11, 629-646. [CrossRef]

58. Dahle, C.; Flechtner, F.; Murböck, M.; Michalak, G.; Neumayer, K.; Abrykosov, O.; Reinhold, A.; König, R. GRACE-FO D-103919 (Gravity Recovery and Climate Experiment Follow-On): GFZ Level-2 Processing Standards Document for Level-2 Product Release 06 (Rev. 1.0, June 3, 2019); Scientific Technical Report STR - Data, 19/09; GFZ German Research Centre for Geosciences: Potsdam, Germany, 2019. [CrossRef]

(C) 2019 by the authors. Licensee MDPI, Basel, Switzerland. This article is an open access article distributed under the terms and conditions of the Creative Commons Attribution (CC BY) license (http:/ / creativecommons.org/licenses/by/4.0/). 